\title{
THE PROFILE OF DEMOGRAPHICS, TRAINING HABITS, AND HEALTH OF RECREATIONAL TRAIL RUNNERS: A COMPARATIVE STUDY AMONG DIFFERENT DISTANCES
}

original paper

( ) University School of Physical Education in Wroclaw

DOI: https://doi.org/10.5114/hm.2021.100324

\section{PATRÍCIA MOLZ}

Graduate Program in Medicine and Health Sciences, School of Medicine, Pontifical Catholic University of Rio Grande do Sul, Porto Alegre, Brazil

\section{ABSTRACT}

Purpose. Despite considerable growth of trail runners' population, little is known about the demographics, training habits, and health characteristics of recreational trail runners. Thus, the aim of this study was to describe the demographics, training habits, and health characteristics of recreational trail runners as compared between different distances of Circuito Trilhas $\&$ Montanhas.

Methods. The descriptive transversal study involved 167 trail runners of Circuito Trilhas \& Montanhas. A questionnaire concerning trail-running practice was applied and the chosen route (short/medium/long) was recorded.

Results. The trail runners were mostly young athletes ( $\leq 40$ years old, $51.5 \%)$, males $(66.5 \%)$, bachelors $(56.3 \%)$, and married or in a committed relationship (58.1\%). Most of the long distance trail runners were significantly more experienced $(p=0.001$; $\varphi=0.230)$, ran $10-20 \mathrm{~km}$ per training $(p<0.001 ; \varphi=0.535)$, participated in club sport $(p=0.004 ; \varphi=0.257)$, and used safety equipment $(p=0.011 ; \varphi=0.233$ ) compared with the other distances. The chosen course was not associated with the health status ( $p=0.385)$, but the presence of diseases was significantly reported by most of the short distance trail runners $(p=0.023 ; \varphi=0.213)$.

Conclusions. The recreational trail runners participating in this study are predominantly young, well-educated, and married. Most long distance trail runners were more experienced, ran average distances per training, participated in club sport, and used safety equipment compared with the other distances. Moreover, trail runners with any diseases ran in short distances.

Key words: trail running, trail race, exercise

\section{Introduction}

Trail running, according to the International Trail Running Association, is a pedestrian race open to all, held in a natural environment (e.g. mountains, desert, forest, plain) with a minimal share of paved or asphalt roads, not exceeding $20 \%$ of the total of the races [1]. Currently, this modality has been attracting numerous followers in several countries, also in Brazil [2, 3].

With the recent increase in the popularity of this modality, many of these events have attracted a significant number of runners who aim at the sport as a form of recreation [4]. However, trail running is a complex sport [5, 6], a new running discipline with distinct physiological characteristics, principally held in chal- lenging environmental conditions owing to harsh trail course topographies [7], leading to major changes in physiological and mechanical responses [8].

Therefore, many participants lack specific knowledge and preparation to deal with this modality. Thus, amateur athletes, self-training, can face problems in completing this type of test within healthy margins because of the compromised sporting performance [9]. In addition, there are medical, nutritional, biochemical, and physiological aspects related to trail-running preparation [10] that may directly influence the performance of runners [11].

A factor that has impacted on an increase in trail runners' population is trail use for wellness and health as trail running has been recommended to increase

Correspondence address: Patrícia Molz, Graduate Program in Medicine and Health Sciences, School of Medicine,

Pontifical Catholic University of Rio Grande do Sul, 6690 Ipiranga Avenue, Porto Alegre, Brazil,

e-mail: patricia.molz@gmail.com

Received: July 18, 2019

Accepted for publication: May 16, 2020

Citation: Molz P. The profile of demographics, training habits, and health of recreational trail runners: a comparative study among different distances. Hum Mov. 2021;22(3):54-61; doi: https://doi.org/10.5114/hm.2021.100324. 
the physical activity of the population [12]. This landscape has often hampered the organization of trailrunning races and the implementation of appropriate safety regulations for all types of competitors [3].

An increasing number of studies are performed to answer the questions concerning physiological and biomechanical factors in trail running [5, 11, 13, 14]. However, the investigation of demographics, training habits, and health characteristics is still very limited and mostly based on ultra-trail runners [15] or trail users [12]. Data on recreational trail runners of lower distances are lacking. Nevertheless, they are of great relevance since they can help health professionals plan actions and strategies for a better performance during the competitions, as well as improve the strategies of test organizers in order to promote better safety for runners.

Therefore, the objective of this study was to describe the demographics, training habits, and health characteristics of recreational trail runners as compared between different distances of Circuito Trilhas \& Montanhas (CTM).

\section{Material and methods}

This descriptive observational study was carried out among trail runners of CTM 2018, between March and December 2018, in Rio Grande do Sul, Brazil. CTM is a sports event composed of 7 steps in a pedestrian race, divided into 3 categories/courses (short/medium/long), carried out in the rural area of the municipalities of the state of Rio Grande do Sul, Brazil. Table 1 shows the characteristics of the races.

All runners of the CTM 2018 who completed at least 1 of the 7 steps were invited to participate in this study. Out of a total of 2040 invited runners, 167 volunteers accepted to participate in the research $(8.2 \%$ of CTM 2018 runners); 47 (26 men) completed the short course, 53 (33 men) completed the medium course, and 67 (52 men) completed the long course. Runners who were under 18 years of age and who did not complete the questionnaire appropriately were excluded from the survey.

Table 1. Characteristics of Circuito Trilhas \& Montanhas

\begin{tabular}{|c|c|c|c|c|c|}
\hline Step & $\begin{array}{l}\text { Distance } \\
(\mathrm{km})\end{array}$ & $\begin{array}{l}\text { Elevation gain } \\
\qquad(\mathrm{m})\end{array}$ & $\begin{array}{l}\text { Starting/finishing } \\
\text { altitude } \\
\text { (m.a.s.l.) }\end{array}$ & $\begin{array}{l}\text { Highest altitude } \\
\text { (m.a.s.l.) }\end{array}$ & $\begin{array}{l}\text { Maximum time } \\
\text { to finish } \\
\text { (h) }\end{array}$ \\
\hline \multirow{3}{*}{ Farroupilha } & 6 & 280 & \multirow{3}{*}{515} & $622(\mathrm{~km} \mathrm{2})$ & 1.5 \\
\hline & 13 & 570 & & $663(\mathrm{~km} \mathrm{11)}$ & 3 \\
\hline & 27.5 & 1120 & & $650(\mathrm{~km} \mathrm{23)}$ & 5 \\
\hline \multirow{3}{*}{ Tupandi } & 5.5 & 260 & \multirow{3}{*}{70} & $290(\mathrm{~km} \mathrm{2})$ & 1.5 \\
\hline & 15.5 & 850 & & $370(\mathrm{~km} \mathrm{11)}$ & 3 \\
\hline & 27.1 & 1290 & & $370(\mathrm{~km} \mathrm{13)}$ & 5 \\
\hline \multirow{3}{*}{ Sério } & 6 & 224 & \multirow{3}{*}{630} & $650(\mathrm{~km} \mathrm{1.5)}$ & 1.5 \\
\hline & 14 & 700 & & $660(\mathrm{~km} \mathrm{7})$ & 3 \\
\hline & 26.9 & 1310 & & $660(\mathrm{~km} \mathrm{22})$ & 5 \\
\hline \multirow{3}{*}{ Arroio do Meio } & 6.5 & 160 & \multirow{3}{*}{80} & $210(\mathrm{~km} \mathrm{3})$ & 1.5 \\
\hline & 16.5 & 720 & & $540(\mathrm{~km} \mathrm{9)}$ & 3 \\
\hline & 27.7 & 1380 & & $540(\mathrm{~km} \mathrm{13)}$ & 6 \\
\hline \multirow{3}{*}{ Nova Roma do Sul } & 6.5 & 170 & \multirow{3}{*}{583} & $634(\mathrm{~km} \mathrm{3)}$ & 1.5 \\
\hline & 12 & 650 & & $634(\mathrm{~km} \mathrm{7})$ & 3 \\
\hline & 29 & 1450 & & $692(\mathrm{~km} \mathrm{8)}$ & 5 \\
\hline \multirow{3}{*}{ Igrejinha } & 7 & 190 & \multirow{3}{*}{50} & $124(\mathrm{~km} \mathrm{2})$ & 1.5 \\
\hline & 14 & 650 & & $270(\mathrm{~km} \mathrm{10})$ & 3 \\
\hline & 33 & 1400 & & $738(\mathrm{~km} \mathrm{21)}$ & 5.5 \\
\hline \multirow{3}{*}{ Rolante } & 5 & 191 & \multirow{3}{*}{465} & $543(\mathrm{~km} \mathrm{2})$ & 1.5 \\
\hline & 17 & 650 & & $692(\mathrm{~km} \mathrm{7})$ & 3 \\
\hline & 28.5 & 1000 & & $830(\mathrm{~km} \mathrm{18)}$ & 5 \\
\hline
\end{tabular}

Highest altitude indicates the highest point in the route; the value in kilometres indicates the location of the highest point within the route.

m.a.s.l. - metres above sea level 
The study participants answered an online questionnaire, sent via social networks, containing 15 closed questions that focused on the demographics, training habits, and health characteristics of trail runners. This questionnaire also included questions about personal data such as gender, age, schooling and marital status to characterize the sample. Moreover, the performed category (short, medium, or long) as well as the time to complete the course were recorded.

Statistical analysis was performed with the Statistical Package for the Social Sciences (SPSS) software, v. 20.0. Continuous data were expressed as mean \pm standard deviation and categorical variables were presented in numbers and percentages. The chi-square test with Cramer's phi $(\varphi)$ was used to evaluate the effect size of the differences and associations. Statistical significance of the results was accepted at $p<0.05$.

\section{Ethical approval}

The research related to human use has complied with all the relevant national regulations and institutional policies, has followed the tenets of the Declaration of Helsinki, and has been approved by the Ethics Committee of the International University Centre (UNINTER) under the protocol number of040859/2018.

\section{Informed consent}

Informed consent has been obtained from all individuals included in this study.

\section{Results}

Table 2 shows the demographic characteristics of the 167 trail runners participating in the study, with a mean age of $39.80 \pm 10.97$ years (range: $18-76$ years) and male predominance $(65.5 \%)$. There was a prevalence of young individuals (up to 40 years of age, $51.5 \%$ ), people with complete higher education (56.3\%), and married ones or those living with a partner (58.1\%). In addition, most of the evaluated runners $(40.1 \%)$ participated in the long course.

The average race times of the study participants were $0.58 \pm 0.18 \mathrm{~h}$ (range: $0.27-1.40$ ), $1.48 \pm 0.44 \mathrm{~h}$ (range: 0.75-2.68), and $2.86 \pm 0.64 \mathrm{~h}$ (range: 1.59 4.28) for the short, medium, and long course, respectively. With respect to the practice of trail running, most of the long distance trail runners were significantly more experienced ( $p=0.001 ; \varphi=0.230)$, ran $10-20 \mathrm{~km}$ per training $(p<0.001 ; \varphi=0.535)$, participated in club sport ( $p=0.004 ; \varphi=0.257$ ), and used safety equipment ( $p=0.011 ; \varphi=0.233$ ) (Table 3).

Among the safety equipment, most used were specific clothing for running, specific shoes for trail running, and backpack/hydration belts $(83.0 \%, 81.7 \%$, and $80.3 \%$, respectively). As for the type of training ground, most trail runners reported training in the city (66.5\%), on dirt roads (50.3\%), and on trails (47.9\%). The performance of another activity to complement the training did not differ between the courses $(p=0.582 ; \varphi=0.081)$;

Table 2. Demographic characteristics of the recreational trail runners of Circuito Trilhas \& Montanhas 2018, Brazil $(n=167)$

\begin{tabular}{|c|c|c|c|c|}
\hline \multirow{2}{*}{ Variable } & \multirow{2}{*}{ All, $n(\%)$} & \multicolumn{3}{|c|}{ Race } \\
\hline & & Short & Medium & Long \\
\hline Number of individuals & 167 & 47 & 53 & 67 \\
\hline \multicolumn{5}{|l|}{ Sex } \\
\hline Female & $56(33.5)$ & $21(37.5)$ & $20(35.7)$ & $15(26.8)$ \\
\hline Male & $111(66.5)$ & $26(23.4)$ & $33(29.7)$ & $52(46.8)$ \\
\hline \multicolumn{5}{|l|}{ Age } \\
\hline$\leq 40$ years & $86(51.5)$ & $24(27.9)$ & $31(36.0)$ & $31(36.0)$ \\
\hline$>40$ years & $81(48.5)$ & $23(28.4)$ & $22(27.2)$ & $36(44.4)$ \\
\hline \multicolumn{5}{|l|}{ Education } \\
\hline Elementary school & $8(4.8)$ & $1(12.5)$ & $3(37.5)$ & $4(50.0)$ \\
\hline High school & $65(39.0)$ & $18(27.7)$ & $23(35.4)$ & $24(36.9)$ \\
\hline Bachelor's degree & $94(56.3)$ & $28(29.8)$ & $27(28.7)$ & $39(41.5)$ \\
\hline \multicolumn{5}{|l|}{ Marital status } \\
\hline Single & $54(32.3)$ & $16(30.2)$ & $21(37.1)$ & $17(32.1)$ \\
\hline Married or in a committed relationship & $97(58.1)$ & $26(26.8)$ & $29(29.9)$ & $42(43.3)$ \\
\hline Divorced or separated & $16(9.6)$ & $5(31.2)$ & $3(18.8)$ & $8(50.0)$ \\
\hline
\end{tabular}


Table 3. Training habits of the recreational trail runners of Circuito Trilhas \& Montanhas 2018, Brazil $(n=167)$

\begin{tabular}{|c|c|c|c|c|c|c|}
\hline \multirow{2}{*}{ Variable } & \multirow{2}{*}{ All, $n(\%)$} & \multicolumn{3}{|c|}{ Race } & \multirow{2}{*}{$p^{*}$} & \multirow{2}{*}{$\varphi$} \\
\hline & & Short & Medium & Long & & \\
\hline Number of individuals & 167 & 47 & 53 & 67 & & \\
\hline $\begin{array}{l}\text { Experience in trail running } \\
<1 \text { year } \\
1-2 \text { years } \\
\geq 3 \text { years }\end{array}$ & $\begin{array}{l}36(21.6) \\
50(29.9) \\
81(48.5)\end{array}$ & $\begin{array}{l}17(47.2) \\
15(30.0) \\
15(18.5)\end{array}$ & $\begin{array}{l}10(27.8) \\
21(42.0) \\
22(27.2)\end{array}$ & $\begin{array}{r}9(25.0) \\
14(28.0) \\
44(54.3) \\
\end{array}$ & 0.001 & 0.230 \\
\hline $\begin{array}{l}\text { Schedule of training } \\
\text { Morning } \\
\text { Afternoon } \\
\text { Night } \\
\geq 2 \text { shifts } \\
\end{array}$ & $\begin{array}{l}41(24.6) \\
38(22.8) \\
49(29.3) \\
39(23.4) \\
\end{array}$ & $\begin{array}{r}15(36.6) \\
12(31.6) \\
13(26.5) \\
7(17.9) \\
\end{array}$ & $\begin{array}{l}12(29.3) \\
14(36.8) \\
15(30.6) \\
12(30.8) \\
\end{array}$ & $\begin{array}{l}14(34.1) \\
12(31.6) \\
21(42.9) \\
20(51.3) \\
\end{array}$ & 0.486 & 0.128 \\
\hline $\begin{array}{l}\text { Average distance per training } \\
<10 \mathrm{~km} \\
10-20 \mathrm{~km} \\
20-30 \mathrm{~km} \\
>30 \mathrm{~km}\end{array}$ & $\begin{array}{c}54(32.3) \\
84(50.3) \\
26(15.6) \\
3(1.8) \\
\end{array}$ & $\begin{aligned} & 38(70.4) \\
& 7(8.3) \\
& 0(0.0) \\
& 2(66.7) \\
&\end{aligned}$ & $\begin{array}{r}12(22.2) \\
37(44.0) \\
3(11.5) \\
1(33.3) \\
\end{array}$ & $\begin{aligned} & 4(7.4) \\
& 40(47.6) \\
& 23(88.5) \\
& 0(0.0) \\
&\end{aligned}$ & $<0.001$ & 0.535 \\
\hline $\begin{array}{l}\text { How is the trail-running training performed } \\
\text { Individually } \\
\text { In group }\end{array}$ & $\begin{array}{r}60(35.9) \\
107(64.1) \\
\end{array}$ & $\begin{array}{l}19(31.7) \\
28(26.2)\end{array}$ & $\begin{array}{l}13(21.7) \\
40(37.4)\end{array}$ & $\begin{array}{l}28(46.7) \\
39(36.4) \\
\end{array}$ & 0.110 & 0.162 \\
\hline $\begin{array}{l}\text { Participation in club sport } \\
\text { No } \\
\text { Yes }\end{array}$ & $\begin{array}{r}33(19.8) \\
134(80.2) \\
\end{array}$ & $\begin{array}{c}2(6.1) \\
45(33.6)\end{array}$ & $\begin{array}{l}16(48.5) \\
37(27.6)\end{array}$ & $\begin{array}{l}15(45.5) \\
52(38.8)\end{array}$ & 0.004 & 0.257 \\
\hline $\begin{array}{l}\text { Use of safety equipment } \\
\text { No } \\
\text { Yes }\end{array}$ & $\begin{array}{r}25(15.0) \\
142(85.0) \\
\end{array}$ & $\begin{array}{l}13(52.0) \\
34(23.9)\end{array}$ & $\begin{array}{r}7(28.0) \\
46(32.4) \\
\end{array}$ & $\begin{array}{r}5(20.0) \\
62(43.7) \\
\end{array}$ & 0.011 & 0.233 \\
\hline $\begin{array}{l}\text { Performing complementary activity } \\
\text { No } \\
\text { Yes }\end{array}$ & $\begin{array}{r}26(15.6) \\
141(84.4)\end{array}$ & $\begin{array}{r}8(30.8) \\
39(27.7)\end{array}$ & $\begin{array}{r}6(23.1) \\
47(33.3)\end{array}$ & $\begin{array}{l}12(46.2) \\
55(39.0)\end{array}$ & 0.582 & 0.081 \\
\hline
\end{tabular}

* chi-square test

Table 4. Health perception of the recreational trail runners of Circuito Trilhas \& Montanhas 2018, Brazil ( $n=167)$

\begin{tabular}{|c|c|c|c|c|c|c|}
\hline \multirow{2}{*}{ Variable } & \multirow{2}{*}{ All, $n(\%)$} & \multicolumn{3}{|c|}{ Race } & \multirow{2}{*}{$p$} & \multirow{2}{*}{$\varphi$} \\
\hline & & Short & Medium & Long & & \\
\hline State of health & & & & & 0.314 & 0.117 \\
\hline $\mathrm{Bad} / \operatorname{good}$ & $75(44.9)$ & $25(33.3)$ & $22(29.3)$ & $28(37.4)$ & & \\
\hline Excellent & $92(55.1)$ & $22(23.9)$ & $31(33.7)$ & $39(42.4)$ & & \\
\hline Presence of diseases & & & & & 0.023 & 0.213 \\
\hline No & 153 (91.6) & $39(25.5)$ & $52(34.0)$ & $62(40.5)$ & & \\
\hline Yes & $14(8.4)$ & $8(57.1)$ & $1(7.1)$ & $5(35.7)$ & & \\
\hline
\end{tabular}

however, $84.4 \%$ of the evaluated individuals practised another activity (Table 3), among which they reported bodybuilding (73.0\%).

Most of the trail runners participating in the survey considered their health status to be excellent (55.1\%) or bad/good (44.3\%), but this was not significantly as- sociated with the chosen course $(p=0.385 ; \varphi=0.112$; Table 4 ). Of the trail runners evaluated, only $8.4 \%$ reported having a health problem. The presence of diseases was significantly more frequently reported by the trail runners of short distance ( $p=0.023 ; \varphi=0.213$ ). Hypertension was the main disease observed (42.9\%). 


\section{Discussion}

The purpose of this study was to characterize the profile of the demographics, training habits, and health of recreational trail runners. The main reason for this subject was an increasing popularity of trail running, which has attracted many types of runners, from amateur athletes to elite-level competitors, and from shortdistance athletes to ultradistance enthusiasts [16].

In the present research, most trail runners reported that they practised trail running for a better quality of life (71.9\%) and leisure (68.3\%), and only a minority perceived the modality as a form of competition (35.9\%). Evidences shows a significant relationship between self-rated health and physical activity $[17,18]$. Corroborating our findings, Smiley et al. [12] also verified an association between trail activity and socialization and stress reduction. Moreover, trail runners, regardless of the mileage travelled or experience in the modality, have an interest in connecting with nature. Many also report becoming addicted to sport from the very first time [16].

On the other hand, this variety of runners has raised numerous special concerns for the race organizers. Although the International Trail Running Association was created with the aim of improving the quality of the race organization and the safety of the participants, the health policy of the Association is mainly focused on antidoping objectives [19]. There is a lack of studies that would determine the profile of trail runners, especially recreational ones. In view of this, the study was conducted to describe the demographics, training habits, and health characteristics of recreational trail runners on different distances in order to emphasize safety during the race to trainers and organizers.

Although trail running is a sport for people of all sexes and ages, our data show that women are still a minority, not reaching $40 \%$ of the total study population. Though this percentage difference has declined over the years, there are usually more men than women in the races [16]. In addition, the increasing female participation in trail running is related to social and safety reasons [20] because women feel safer in outdoor activities when these are conducted in a group [21].

In the present study, we found a similar prevalence of young and master athletes. This is a common feature of trail-running competitions. An increasing participation of master athletes (individuals aged over 40 years) has been observed [13], though this is the age at which the first decline in peak performance occurs [22]. Data recorded by Easthope et al. [13] show a sig- nificant decline in maximum power generation capacities in young $(-32 \%)$ and master athletes $(-40 \%)$ after 1 hour of trail running, possibly owing to the aging process that produces structural and functional transformations, leading to a general decline in physical capacity.

We also demonstrated no significant difference between the performance of young and master athletes in the short ( $p=0.650)$, medium ( $p=0.316)$ or long ( $p=0.076)$ course. Our results corroborate studies which have shown that master endurance athletes are able to maintain their performance despite exhibiting structural changes in muscles and maximal aerobic power changes related to aging [22, 23].

The CTM participants presented good levels of education, that is, had completed higher education (56.3\% of the global sample and $41.5 \%$ of the long course runners). Similar result were observed by Smiley et al. [12], who found that more than $65 \%$ of trail users evaluated in the state of Indiana, USA had a college education or advanced degree. The authors also suggest that trail users, on the whole, are wealthier and more educated.

Moreover, although we do not have specific data regarding the occupation of the trail runners in this study, our data corroborated the demographic characteristics of 489 ultramarathon trail participants of the Western States Endurance Run and the Vermont 100 Endurance Race (VT 100). The authors verified that $43.5 \%$ of the participants had a bachelor's degree, suggesting that individuals who ventured over long distances occupied professional and business areas [15].

Most of the trail runners of the present study were in a stable relationship (58.1\%); these data are lower than those in the study by Smiley et al. [12], in which the majority of the runners in the state of Indiana, USA were married (67.0\%). Also in the long course, most of the trail runners in our study were in a stable relationship (62.7\%); these data are lower than those in the study by Hoffman and Fogard [15], in which the majority of the ultra-trail runners were generally in a stable relationship (70.1\%).

According to prospective studies [2, 13, 23], trail running promotes a strenuous physical load on the organism and may cause severe structural damage to the muscles. In view of this, all trail runners of the present research finished the race within the time limit stipulated by the organization; however, $25.8 \%(n=31)$ of the participants of the medium and long courses arrived at a time above that considered physiologically adequate for this modality, which indicates poor preparation for the race.

Additionally, the large number of trail runners in 
our study who were unprepared need to find adaptations that will empower them to finish a trail race safely. Thus, it becomes relevant to identify internal and external strategies that can be used by runners during races and/or trainings, in an attempt to reduce the physiological changes usually reported after trail running. Giandolini et al. [8], reported that muscle fatigue and mechanical muscle damage largely contributed to the decline of trail-running performance. Fatigue resistance, power, and muscle strength are important for trail-running race time $[5,6,14]$.

In the present study, most runners had practised trail running for 3 years or more and competed in the long run. Our data corroborate the study by Hoffman and Fogard [15], in which trail ultramarathon runners had practised such events for an average of 7.6 years, which indicates that the longer the practice, the longer the travelled distance. In addition, we observed that the training schedule did not differ between groups, although it should be noted that only $22.8 \%$ of the evaluated trail runners trained in the afternoon, the period of CTM races.

In line with our findings, Karlsen et al. [24] pointed out that the choice of day period interfered significantly in the performance of sports. Moreover, it has been shown that changes in ambient temperature and humidity seem to affect sports performance more than the period of the day [25]. The environment temperature and humidity also directly influenced the performance of trail runners in our study; in the Salto Ventoso race in Farroupilha, the temperature reached $32^{\circ} \mathrm{C}$, with a thermal sensation of $40^{\circ} \mathrm{C}$, which resulted in the highest percentage of waivers $(5.4 \%, n=60)$ and a higher number of services by the health-care staff.

Another factor that may influence the training schedule is the daily life activities (e.g. work, family, social relationships), being a challenge for recreational trail runners [2] and causing a large number of runners evaluated in this research to do their training at night (29.3\%) and in the city (66.5\%). Moreover, 50.3\% of runners trained $10-20 \mathrm{~km}$ per training and only $34.3 \%$ of the long course runners trained close to the mileage of the race (20-30 km per training). It must be taken into account that in trail running, progress denotes gradually increasing the trail, with minutes or hours as a guide, not distance [16]. However, care must be taken to avoid overloading the body, which would contribute to the decline in trail-running performance [7].

The present study showed that most CTM participants used safety equipment when practising the sport; the equipment mainly included specific clothes for running, backpack/hydration belts, and specific shoes for trail running. The clothes suitable for trail running are quite basic, aiming to moderate body temperature and perspiration and to provide protection against the elements [16]. Among the major external strategies used during trail running is wearing compression garments, although there is no definite consensus about their effects [26] and no evidence on their physiological benefits in trail running at lower distances [27].

Another safety factor pointed out by the CTM runners is the use of a backpack/hydration belt, which, according to Chase and Hobbs [16], depending on the duration of the trail, is an important item, since one should always carry some type of hydration system and a little food, plus a first aid kit for possible emergencies. The specific shoes, having traction and cushioning against obstacles of the track, also constitute significant trail-running safety equipment, frequently used by the CTM runners [16].

Trail running is not generally a club sport [2]; however, $80.2 \%$ of the runners evaluated in the present study participated in club sport and $64.1 \%$ practised group sports. Possibly, the trail runners of the present study were looking for an organizational structure for training, which is often advised by qualified professionals. In addition, this emphasizes that the majority of the participants aimed at trail running as a form of leisure, as discussed previously, as well as a modality to be carried out in a group.

In the present study, the main complementary activity among the CTM runners was bodybuilding, a type of exercise that aims at muscle recovery. Trail running involves many uphill and downhill running sections [13], imposing intensive physiological demands on the musculature and altering biomechanics [28]. Strategies to minimize the cost of running are important in shorter distances [6] and strength training; muscular recovery is of great importance in trail runners because of the damages caused by the race [29].

CTM has a short course, around $6 \mathrm{~km}$, in which $68.1 \%$ of the participants from this distance had up to 2 years of experience. This is due in part to the fact of the increased number of trail runners [3] because of the positive effects of recreational walking and running on health outcomes and because of the easier access to trails [12]. Moreover, trail running may be a considerable tool against obesity and depression among individuals with low physical activity [12].

With respect to the state of health of the trail runners evaluated in this study, 55.1\% of them reported excellent health, and $91.6 \%$ did not present any health problems that might limit their track activities. It is 
known that before starting a new physical exercise program, one should first perform a medical evaluation to determine if there are any limitations to exercise [16].

Moreover, for the sake of CTM participants' security, health-care staff is present at all stages to attend possible complications. The technical and geographical particularities of trail-running races are a real challenge for the health-care staff; however they must be prepared for different situations, such as digestive problems, diseases related to the environment, and musculoskeletal injuries, which may often require rapid and effective intervention [30].

Indicating the demographics, training habits, and health characteristics of recreational trail runners and their association with different distances (short, medium, and long) is the strength of this study. It is suggested that this is one of the first studies related to these variables with a focus on recreational trail runners in the literature. Although the self-report nature of data collection could be considered as a bias, the questions did not require the respondents to recall long-term details of running habits, which makes the survey tool reliable.

A further study limitation may be a sampling bias, with a low (8.2\%) representation of the CTM 2018 participants. Additionally, several important lifestyle characteristic, such as nutritional status, smoking status, medication use, physical activity level, and diet, were not evaluated. Anyway, the study results may support coaches in creating sustainable training and competition strategies and help organizers promote better safety for runners.

\section{Conclusions}

The present study shows an overview of the CTM 2018 participants' demographics, training habits, and health characteristics. Our results imply that CTM trail runners are mostly young, well-educated, married or in a committed relationship. With regard to the characteristics of the trail-running practice and the distance covered (short/medium/long), it was observed that most long distance trail runners were more experienced, ran average distances per training, participated in club sport, and used safety equipment. The results indicate the existence of a diversified profile of runners, who mostly aim at trail running as a form of leisure, as well as a modality to be performed in a group. However, the course was not associated with the state of health; the majority reported having excellent health status. Moreover, a minority of the runners presented some disease; health issues prevailed among short distance trail runners.

\section{Acknowledgements}

The author is grateful to all participants in the study, as well as to L\&E Eventos, the organizing committee of the Circuito Trilhas \& Montanhas, for agreeing to carry out this work, and to 3CTiming Cronometragem Eletrônica and to YouMovin for help in data collection.

\section{Disclosure statement}

The author does not have any financial interest and did not receive any financial benefit from this research.

\section{Conflict of interest}

The author states no conflict of interest.

\section{References}

1. International Trail Running Association. Definition of trail-running. 2019. Available from: https:/itra.run/ page/259/Definition_of_trail-running.html.

2. Rochat N, Hauw D, Gür G, Seifert L. Understanding trail runners' activity on online community forums: an inductive analysis of discussion topics. J Hum Kinet. 2018;61(1):263-276; doi: 10.1515/hukin-2017-0125.

3. Olmedillas H. Performance factors in trail-running. Arch Med Deporte. 2018;35(1):6-7.

4. Taksaudom N, Tongsiri N, Potikul A, Leampriboon C, Tantraworasin A, Chaiyasri A. Race predictors and hemodynamic alteration after an ultra-trail marathon race. Open Access J Sports Med. 2017;8:181-187; doi: 10.2147/ OAJSM.S142040.

5. Ehrström S, Tartaruga MP, Easthope CS, Brisswalter J, Morin J-B, Vercruyssen F. Short trail running race: beyond the classic model for endurance running performance. Med Sci Sports Exerc. 2018;50(3):580-588; doi: 10.1249/MSS.0000000000001467.

6. Scheer V, Janssen TI, Vieluf S, Heitkamp H-C. Predicting trail-running performance with laboratory exercise tests and field-based results. Int J Sports Physiol Perform. 2019;14(1):130-133; doi: 10.1123/ijspp.20180390.

7. Costa RJS, Knechtle B, Tarnopolsky M, Hoffman MD. Nutrition for ultramarathon running: trail, track, and road. Int J Sport Nutr Exerc Metab. 2019;29(2):130-140; doi: 10.1123/ijsnem.2018-0255.

8. Giandolini M, Vernillo G, Samozino P, Horvais N, Edwards WB, Morin JB, et al. Fatigue associated with prolonged graded running. Eur J Appl Physiol. 2016;116(10): 1859-1873; doi: 10.1007/s00421-016-3437-4.

9. Llopis Goig D, Llopis Goig R. Reasons for participating in long distance races. A study with amateur runners [in Spanish]. Cult Cienc Deporte. 2006;2(4):33-40; doi: 10.12800/ccd.v2i4.168. 
10. Scheer V, Vieluf S, Janssen TI, Heitkamp H-C. Predicting competition performance in short trail running races with lactate thresholds. J Hum Kinet. 2019;69:159-167; doi: 10.2478/hukin-2019-0092.

11. Easthope CS, Nosaka K, Caillaud C, Vercruyssen F, Louis J, Brisswalter J. Reproducibility of performance and fatigue in trail running. J Sci Med Sport. 2014; 17(2):207-211; doi: 10.1016/j.jsams.2013.03.009.

12. Smiley A, Ramos WD, Elliott LM, Wolter SA. Association between trail use and self-rated wellness and health. BMC Public Health. 2020;20(1):128; doi: 10.1186/ s12889-020-8273-0.

13. Easthope CS, Hausswirth C, Louis J, Lepers R, Vercruyssen F, Brisswalter J. Effects of a trail running competition on muscular performance and efficiency in well-trained young and master athletes. Eur J Appl Physiol. 2010;110(6):1107-1116; doi: 10.1007/s00421010-1597-1.

14. Balducci P, Clémençon M, Trama R, Blache Y, Hautier C. Performance factors in a mountain ultramarathon. Int J Sports Med. 2017;38(11):819-826; doi: 10.1055/ s-0043-112342.

15. Hoffman MD, Fogard K. Demographic characteristics of 161-km ultramarathon runners. Res Sports Med. 2012;20(1):59-69; doi:10.1080/15438627.2012.634707.

16. Chase AW, Hobbs N. The ultimate guide to trail running: everything you need to know about equipment, finding trails, nutrition, hill strategy, racing, avoiding injury, training, weather, safety. Guilford: Globe Pequot Press; 2010.

17. Girón P. Determinants of self-rated health in Spain: differences by age groups for adults. Eur J Public Health. 2012;22(1):36-40; doi: 10.1093/eurpub/ckq133.

18. Dong W, Wan J, Xu Y, Chen C, Bai G, Fang L, et al. Determinants of self-rated health among Shanghai elders: a cross-sectional study. BMC Public Health. 2017;17(1): 807; doi: 10.1186/s12889-017-4718-5.

19. International Trail Running Association. Health policy. 2019. Available from: https://itra.run/page/377/Health_ policy.html.

20. Navalta JW, Montes J, Tanner EA, Bodell NG, Young JC. Sex and age differences in trail half marathon running. Int J Exerc Sci. 2018;11(6):281-289.

21. Wesely JK, Gaarder E. The gendered "nature" of the urban outdoors: women negotiating fear of violence. Gender Soc. 2004;18(5):645-663; doi: 10.1177/0891 243204268127.

22. Lepers R, Sultana F, Bernard T, Hausswirth C, Brisswalter J. Age-related changes in triathlon performances. Int J Sports Med. 2010;31(4):251-256; doi: 10.1055/s0029-1243647.

23. Bieuzen F, Brisswalter J, Easthope C, Vercruyssen F, Bernard T, Hausswirth C. Effect of wearing compression stockings on recovery after mild exercise-induced muscle damage. Int J Sports Physiol Perform. 2014;9(2): 256-264; doi: 10.1123/ijspp.2013-0126.
24. Karlsen A, Nybo L, Nørgaard SJ, Jensen MV, Bonne T, Racinais S. Time course of natural heat acclimatization in well-trained cyclists during a 2-week training camp in the heat. Scand J Med Sci Sports. 2015; 25(Suppl. 1):240-249; doi: 10.1111/sms.12449.

25. Boukelia B, Gomes EC, Florida-James GD. Diurnal variation in physiological and immune responses to endurance sport in highly trained runners in a hot and humid environment. Oxid Med Cell Longev. 2018;2018: 3402143; doi: 10.1155/2018/3402143.

26. Kerhervé HA, Samozino P, Descombe F, Pinay M, Millet GY, Pasqualini M, et al. Calf compression sleeves change biomechanics but not performance and physiological responses in trail running. Front Physiol. 2017; 8:247; doi: 10.3389/fphys.2017.00247.

27. Vercruyssen F, Gruet M, Colson SS, Ehrstrom S, Brisswalter J. Compression garments, muscle contractile function, and economy in trail runners. Int J Sports Physiol Perform. 2017;12(1):62-68; doi: 10.1123/ijspp. 2016-0035.

28. Alvero-Cruz JR, Parent Mathias V, Garcia Romero J, Carrillo de Albornoz-Gil M, Benítez-Porres J, Ordonez FJ, et al. Prediction of performance in a short trail running race: the role of body composition. Front Physiol. 2019;10:1306; doi: 10.3389/fphys.2019.01306.

29. Berryman N, Mujika I, Arvisais D, Roubeix M, Binet C, Bosquet L. Strength training for middle- and long-distance performance: a meta-analysis. Int J Sports Physiol Perform. 2018;13(1):57-64; doi: 10.1123/ijspp.20170032.

30. Sollander F, Porzi J, Servant G, Gojanovic B, Dussoix P. Trail running: a challenge for medical support teams [in French]. Rev Med Suisse. 2019;15(658):1370-1373. 